\title{
Blindness in Africa: present situation and future needs
}

\author{
Susan Lewallen, Paul Courtright
}

\begin{abstract}
Aim-To review the prevalence and causes of blindness in sub-Saharan Africa, the existing services and limitations, and the Vision 2020 goals for the future.

Methods-Methodologically sound population based surveys published in the past 20 years are reviewed and results for prevalence and causes of blindness are tabulated. The current resources and needs according to recent publications and international working groups are described.

Conclusions-Blindness prevalence rates vary widely but the evidence suggests that approximately $1 \%$ of Africans are blind. The major cause is cataract; trachoma and glaucoma are also important causes of blindness. The bulk of blindness in the region is preventable or curable. Efforts should focus on eye problems which are universally present and for which there are cost effective remedies, such as cataract and refractive problems and on those problems which occur focally and can be prevented by primary healthcare measures, such as trachoma, onchocerciasis, and vitamin A deficiency. Major development of staffing levels, infrastructure, and community programmes will be necessary to achieve Vision 2020 goals.

(Br F Ophthalmol 2001;85:897-903)
\end{abstract}

Africa is a vast and varied continent. The northern countries of the continent (Morocco to Egypt) are distinct in numerous ways and for purposes of describing and planning for health, the World Health Organization (WHO) includes only sub-Saharan Africa in the region. We will do the same in this paper, and use the word Africa to refer to sub-Saharan Africa. This region is home to approximately 7.1 of the world's 38 million blind (WHO/PBL/97.61 Rev 2). We will review the current information on the epidemiology of blindness and eye diseases, eye care service availability and use, and future needs and plans for reducing the burden of blindness.

Current blind and causes

A computer based search of the English and French literature (Medline 1966-98, Embase
1976-98, Healthstar 1975-97, current Contents 1996-9, Scisearch 1974-98, and Biosis 1969-98) reveals a number of published blindness surveys from Africa. We chose those that met the following criteria: (1) methodologically acceptable population based surveys including (but not limited to) adults, (2) minimum sample size of 1000, and (3) published between 1980-2000. Most of these surveys included data on the causes of blindness although diagnostic criteria were not uniform. There were 22 surveys that met the criteria ${ }^{1-22}$; these are shown in Table 1. Overall, these surveys suggest that approximately $1 \%$ of Africa's population is blind (using the WHO criteria of $<3 / 60$ ). As elsewhere in the world, women account for approximately $60 \%$ of the blind; the age adjusted odds of blindness in women is 1.39 (95\% CI 1.29-1.54) times higher than the odds of blindness in men. ${ }^{23}$

CATARACT

As demonstrated by these surveys, approximately half the blindness in Africa is due to cataract. The prevalence of blinding bilateral cataract in Africa is estimated to be around $0.5 \%$; however, this figure is obviously dependent on the regional rate of cataract surgery. There is no reliable information on the incidence of cataract among Africans. Studies of race as a risk factor for cataract have been done in the United States and the Caribbean but it may not be valid to generalise these findings to Africa since there are many differences in other risk factors (notably diabetes) between the populations. ${ }^{24}{ }^{25}$ As elsewhere, females have slightly higher rates of cataract incidence for reasons that are not completely known. The main area of interest concerning cataract is in the development of service delivery.

TRACHOMA

Although trachoma has been declining in many areas of the world, it still remains the second leading cause of blindness in Africa. Estimates suggest that approximately 2.2 million people are blind from trachoma in Africa (K Frick, personal communication). Trachoma exists throughout much of sub-Saharan Africa (Fig $1)$. In some areas there is inadequate information to estimate the burden of disease. The bulk of research on trachoma has been carried out in Tanzania, ${ }^{26-28}$ the Gambia, ${ }^{29}{ }^{30} \mathrm{Mali}^{31}$ 
and Malawi. ${ }^{32}$ These investigations have shown that women account for about $75 \%$ of all trachomatis trichiasis and subsequent blindness due to corneal scarring. ${ }^{33}$ Although the prevalence of active disease is similar for boys and girls, adult women tend to have more active disease than adult men, probably due to their more frequent interaction with children. In some areas trachoma is holoendemic - every child acquires active trachoma and every adult shows evidence of conjunctival scarring. At any one time, rates of active disease in children range as high as $50 \%$.

The risk of acquiring Chlamydia trachomatis in Africa is strongly linked with environmental and behavioural characteristics and reduction of disease is strongly linked with improvements in these characteristics. Reducing fly densities in rural African villages has been demonstrated to reduce active disease ${ }^{30}$ as has the introduction of face washing. ${ }^{28}$

GLAUCOMA

The epidemiology of glaucoma is not as clear. There have been many anecdotal reports of high rates of open angle glaucoma (OAG) in Africans, and this seems to begin in a younger age group than among white people. Efforts to understand more about the magnitude and distribution of glaucoma in Africa have usually been limited by reliance on clinic populations and inadequate definitions of glaucoma. None the less, the surveys indicate that OAG is an important cause of blindness in Africa. Reports indicate that most people with glaucoma are not aware of having it and at least half of eyes are already blind at presentation. ${ }^{34}$ Two population based studies of glaucoma with strict definitions have been completed. The first, in the Western Cape of South Africa, reported a prevalence of OAG of $1.5 \%$ while the prevalence of primary angle closure glaucoma was $2.3 \% .^{36}$ The population in this study includes a distinctive ethnic mix of mainly South East Asian ancestry mixed with east African and European and it is not representative of the bulk of sub-Saharan Africa. The second study was in Tanzania, where researchers found a prevalence of open angle glaucoma of $3.1 \%(95 \%$ CI $=2.5-3.8)$ in people over the age of $40 . .^{35}$ This is similar to the prevalence among African Americans and among people of African origin in the Caribbean. ${ }^{37-40}$ In the Tanzanian population OAG accounted for 5\% of all blindness. The prevalence of angle closure glaucoma in Tanzania was only $0.6 \%$, again similar to that found among African Americans.

\section{ONCHOCERCIASIS}

Onchocerciasis or river blindness is still endemic in 30 countries in Africa, and probably accounts for $99 \%$ of the estimated 270000 blind due to onchocerciasis worldwide. ${ }^{41}$ Onchocerciasis is very focal in its distribution, limited to the belt that stretches from Senegal in the west to Ethiopia in the east and south to Malawi. Blinding onchocerciasis is primarily limited to west Africa. Many onchocerciasis endemic areas in eastern Africa have little or no blindness associated with infection.

Table 1 Prevalence and causes of blindness and low vision

\begin{tabular}{|c|c|c|c|c|c|c|}
\hline \multirow[b]{2}{*}{ Country (reference) } & \multirow{2}{*}{$\begin{array}{l}\text { Prevalence of blindness and/or } \\
\text { [low vision] }{ }^{\star}\end{array}$} & \multirow[b]{2}{*}{ Age group examined } & \multicolumn{4}{|c|}{ Proportion of bilateral blindness [low vision] due to: } \\
\hline & & & Cataract & Trachoma & Glaucoma & Cornea \\
\hline $\operatorname{Benin}(1)$ & $\begin{array}{l}0.6(0.4-0.9) \\
{[2.6(2.1-3.1)]}\end{array}$ & All & 54 [63] & [4] & $15[3.4]$ & $11 \dagger$ \\
\hline Cameroon $(2) \ddagger$ & 1.2 & $6+$ & 55 & 7.4 & & \\
\hline $\begin{array}{l}\text { Central African Republic } \\
\text { (3) } \Omega\end{array}$ & $\begin{array}{l}2.2(1.83-2.57) \\
{[3.0(2.53-3.38)]}\end{array}$ & All & $16.4[54]$ & $4.5[1.7]$ & $2.2[0]$ & \\
\hline Congo (4) & $0.3[2.1]$ & All & $81[80]$ & & 9 [3.4] & \\
\hline Ethiopia (5) & 1.83 & $7+$ years & & & & \\
\hline Ethiopia (6) & $\begin{array}{l}0.85(0.63-1.07) \\
{[1.7(1.4-1.9)]}\end{array}$ & All & 47.7 & 20.6 & 9.5 & \\
\hline Ethiopia (7) & $1.9(1.1-2.9)$ & All & 47 & & & $26+$ \\
\hline The Gambia (8) & $0.7[1.4]$ & All & $45[57]$ & 17 & 2 & $20[13] \uparrow$ \\
\hline Ghana (9) & $1.7(1.1-2.5)$ & $30+$ years & $62.5[51.5]$ & $0[0]$ & $0[0]$ & $8.2[10.3]$ \\
\hline Kenya (10) & $0.7[2.5]$ & All & $38(39)$ & $18.7(12.9)$ & 8.6 & \\
\hline Malawi (11) & $1.27(0.76-1.96)[2.0]$ & $6+$ years & $40[58]$ & & $15[3.2]$ & $30[6.5]^{\star \star}$ \\
\hline Mali (12) & $1.7[1.7]$ & All & $68.7[63.3]$ & 12.1 & 8.1 & \\
\hline Niger (13) & 1.67 & All & 59 & & 2.4 & \\
\hline Nigeria (14) & $11.8+\dagger[16.1]$ & All & & & & \\
\hline Nigeria (15) & $0.33(0.06-0.6)[1.08]$ & All & $70.6[82]$ & & $17.6[4.4]$ & \\
\hline Nigeria (16) & $0.9(0.84-0.96)$ & All & 48 & & & \\
\hline South Africa (17) & $\begin{array}{l}1.0(0.7-1.2) \\
{[1.4(1.1-1.7)]}\end{array}$ & All & $59[68.2]$ & & $23[4.7]$ & \\
\hline South Africa (18) & $0.57(0.46-0.68)$ & All & 55 & 10 & 6 & \\
\hline Sudan (19) & $6.4[4.7]$ & All & & & & \\
\hline Tanzania (20) & $1.26(0.8-1.89)[1.04]$ & $7+$ years & $22[31]$ & $26[15.8]$ & 17.4 & $17.4[15.9]$ \\
\hline Togo (21) $\neq \ddagger$ & 0.82 & All & $39-70$ & $0.9-10.7$ & $3.6-7.6$ & \\
\hline Zambia (22) & $3.6[12.1]$ & $6+$ years & [54] & & & {$[24] \dagger$} \\
\hline
\end{tabular}

${ }^{\star}$ Blindness is defined as $<3 / 60$ by all surveys except Sudan, where blindness is $<6 / 60$. Low vision is $<6 / 18, \geqslant 3 / 60$ except for the following: Sudan $<6 / 18$, $\geqslant 6 / 60$; Benin $<6 / 60, \geqslant 3 / 60$ (95\% confidence intervals, when provided).

tThese might have included some blindness from trachoma.

¥Causes of blindness include blindness and low vision combined.

§Survey was in an onchocerciasis endemic region where onchocerciasis accounted for $73 \%$ of blindness.

TThis includes phthisis bulbi.

${ }^{\star \star}$ At the time of this survey this region was known for vitamin A deficiency.

t†Survey in an onchocerciasis endemic region.

†Survey covered four separate regions in which the causes of blindness varied. Prevalence is for all regions combined. 


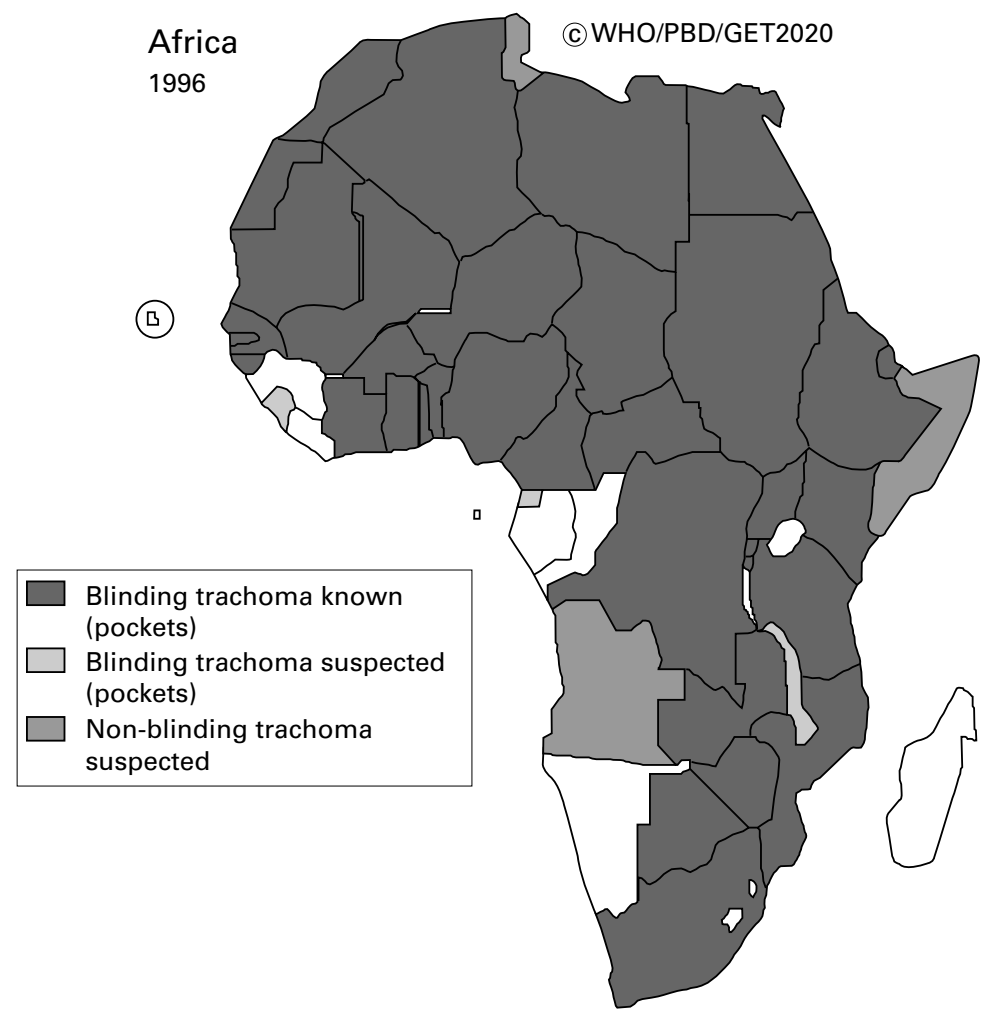

Figure 1 Trachoma in Africa. (Figure provided by the World Health Organization; prepared by Dr Silvio Mariotti.)

TRAUMA

Trauma is a significant cause of monocular blindness. In population based surveys of blindness, the percentage of monocular blindness due to trauma or corneal scar (some of which is presumed to be due to trauma) ranges from $20-50 \%$. In a few surveys trauma was listed as a cause (3.2-5.5\%) of bilateral blindness. ${ }^{13} 1718$ Hospital based studies of eye trauma indicate that about two thirds of those affected are male, predominantly children and young adults. ${ }^{42} 43$ Injuries with sticks, stones, and metallic objects are the most common. ${ }^{42-44}$ The use of traditional eye medicine (TEM) is very common. Forty nine per cent of patients hospitalised for eye trauma in one study ${ }^{44}$ and $59 \%$ of patients with corneal ulcers in another ${ }^{45}$ admitted to using TEM. The use of TEM (especially direct instillation in the eye) potentially worsens otherwise benign conditions and it delays treatment for serious injury and disease. ${ }^{44} 46$

DIABETIC RETINOPATHY

There is ample evidence that diabetic retinopathy occurs among African diabetics who attend clinics in urban centres in Africa. The prevalence of retinopathy of all types ranges from approximately $15-50 \%$ in the clinic populations that have been studied. ${ }^{47-56}$ There is no information, however, on the proportion of diabetics who attend clinics. It is safe to say that treatment for diabetes in general is poor in Africa and very few diabetics have access to treatment for retinopathy. When general diabetic care improves and life expectancy increases, is it likely that more blindness from diabetic retinopathy will occur.
CHILDHOOD BLINDNESS

The prevalence of blindness among children is much lower than among adults; it is estimated that there are around 300000 blind children in Africa (WHO Fact Sheet No 214, February 1999). Gilbert et al identified five population based prevalence surveys of childhood blindness from Africa. ${ }^{57}$ Owing to methodological differences, these surveys are difficult to compare; however, the prevalence of blindness ranged from 0.5 to 1.1 per 1000 children with the highest prevalence reported in an area in Malawi, once known for vitamin A deficiency. In general, the prevalence of blindness is related to the general level of nutritional care of infants and young children. It is estimated that countries with under 5 mortality rates in excess of 170/1000 have a prevalence of childhood blindness in excess of $1 / 1000$, while those with under 5 mortality rates below 30/1000 probably have a prevalence of $0.2-0.5 / 1000$ children. ${ }^{58}$ In poor countries it is estimated that $60-80 \%$ of blind children die within $1-2$ years of becoming blind.

Most data on causes of childhood blindness come from surveys of blind schools. Corneal scar/phthisis bulbi is the leading (36\%) anatomical cause of blindness and severe visual impairment in reports from west Africa (Togo, Benin, Ghana), followed by retinal disease $(20 \%) .^{59}$ In east and southern Africa, corneal scar/phthisis bulbi accounted for $75 \%$ and $49 \%$ of blindness and severe visual impairment in Zimbabwe and Malawi respectively but only $17 \%$ and $20 \%$ in Kenya and Uganda, respectively ${ }^{6061}$ Lower rates of corneal blindness may reflect improved measles immunisation coverage rates, emphasising the relation between childhood blindness and general health care in the evolving epidemiology of childhood blindness. The bulk of childhood blindness is either preventable or treatable.

Vitamin A deficiency not only may cause blindness through the development of keratomalacia, but it is a common cause of mortality in children. Currently, 23 countries have clinical deficiency, 14 have subclinical deficiency, and seven have insufficient data but the possibility of vitamin A deficiency. In only two countries (Mauritius and the Seychelles, where data were also insufficient) was vitamin A deficiency thought to be unlikely. ${ }^{62}$ Within countries, vitamin A deficiency occurs in localised areas related to dietary habits, breastfeeding practices, recent drought, and the prevalence of infectious diseases (many of which can rapidly deplete vitamin A stores and precipitate a crisis in children with marginal reserves). The association of measles or a recent history of measles with corneal ulceration has been well documented. ${ }^{63}$

\section{OTHER DISEASES}

Leprosy is a public health problem in many countries in Africa, especially in Madagascar, Mozambique, and Ethiopia. ${ }^{64}$ Among 26 countries reporting, there were 64490 on current antileprosy treatment and 645576 cured with current antileprosy treatment. There is little information on the ocular status of the 
individuals. A study of 678 self selected leprosy patients $(25 \%$ of the registered cases) in one district in Uganda revealed that $2.2 \%$ of these had a vision less than $6 / 60 ; 60 \%$ of this was due to leprosy related causes. ${ }^{65}$ Although cataract occurs more often in multibacillary leprosy patients than in the general population, exactly how much more has not been determined. Lagophthalmos is likely to affect $2-5 \%$ of cured or active leprosy patients and without surgical intervention corneal damage is not uncommon. ${ }^{6}$ Leprosy patients are at a disadvantage for receiving either cataract or lagophthalmos surgery; limited eye care services are often not accessible to them because of cost, stigma, or other limiting disabilities.

Natural refractive error is not a significant cause of blindness in most of the population based surveys. A small study in Malawi ${ }^{67}$ indicates that refractive error among students is not of the magnitude that has been recently reported from Asia. ${ }^{68-70}$ However, refractive error is a significant cause of low vision (vision less than $6 / 18$ but better than or equal to $3 / 60$ ). Myopia was responsible for $9 \%$ of low vision in a South African survey. ${ }^{17}$ In studies of self presenters in South Africa, Nigeria, and Uganda $^{71-73}$ refractive error (mostly presbyopia) was found to be the single most important diagnosis in $70 \%, 37.4 \%$, and $48 \%$ of patients respectively. In Nigeria refractive error was the cause of $59 \%$ of visual loss in those between 5 and 15 years of age. ${ }^{72}$ Presbyopia is universal in older populations but rarely considered in surveys. Uncorrected aphakia is a cause of blindness in some regions, accounting for $9 \%$, $8 \%, 4.8 \%$, and $4 \%$ of blindness in surveys in South Africa, ${ }^{18}$ the Gambia, ${ }^{8}$ Ethiopia, ${ }^{6}$ and Ghana ${ }^{9}$ respectively.

Retinal diseases as a whole generally account for less than $5 \%$ of blindness in surveys; age related macular degeneration (AMD) is generally considered to be uncommon in Africans. However, several reports document its existence in selected populations in Nigeria. ${ }^{74} 75$

In view of the epidemic of HIV/AIDS in Africa, it is important to mention the ocular manifestations of this. Conjunctival squamous cell carcinoma and herpes zoster ophthalmicus, both HIV related, have become more common and increase the burden on outpatient services ${ }^{76}{ }^{77}$; however, these are not causes of bilateral blindness. Cytomegalovirus retinitis, the major blinding complication of AIDS in the West has been documented in Africa but the high mortality from HIV related conditions limits the incidence of blindness from opportunistic ocular complications. ${ }^{78}$

\section{Existing services and use of services}

The shortage of staff to provide eye care in Africa is legendary. In an editorial in 1991, Allen Foster pointed out that there were only about 50000 blind cataract patients being operated on each year, while there was an annual incidence of 500000 new cataract blind and a backlog of three million. ${ }^{79}$ The ophthalmologist/population ratio was about 1:1 million with some regional variation. The practical ratio is less as most ophthalmologists are in the capital cities. There were four French speaking and eight English speaking countries with programmes to train ophthalmologists. Excluding South Africa, about 50 new ophthalmologists were trained each year. In the decade since this editorial was written, the staff situation has not changed dramatically. Many African countries have recognised this shortage and several have established training programmes for ophthalmic assistants. Duties of these paramedical workers usually include diagnosis, refraction, medical treatment of eye diseases, and minor surgical procedures. A few of the experienced assistants are also trained as cataract surgeons. The assistants and cataract surgeons are usually stationed at district level hospitals and clinics outside the major cities. It is critical that services be available at this level since the majority of Africa's population is rural.

With the low numbers of ophthalmologists and cataract surgeons in Africa, it may seem paradoxical that in most places they are not overwhelmed with cataract surgery. It has become apparent that the patients who present for cataract surgery represent only a small proportion of the cataract blind in the community. The only published cataract surgical coverage data from Africa, conducted in KwaZulu Natal, showed that only $36.7 \%$ of the cataract blind had surgery. ${ }^{18}$ Findings from recent survey in Malawi demonstrated a cataract surgical coverage rate of $26 \%$ (authors' data). Trichiasis surgical coverage has been reported to be $18 \%$ in Tanzanian women ${ }^{80}$ and $38 \%$ in Malawian women. ${ }^{81}$

There are a few investigations into the barriers that prevent people from presenting for cataract surgery ${ }^{82} 83$ or trichiasis surgery ${ }^{80} 81$ in Africa. These overlapping barriers include:

- Cost: This includes not only the cost of the actual operation, but less obvious costs such as transportation to the hospital, loss of work, and living expenses while in hospital as well. Additional costs will exist for a caregiver or guardian who is usually required to accompany a patient.

- Accessibility of services: Since most Africans are rural and the eye care services are in the cities, a journey, often a major one, is necessary to reach the service. However, while high quality cataract surgery generally requires a fixed facility, trichiasis surgery can be done in rural villages. ${ }^{84}$

- Knowledge of services: Lack of awareness that cataract or trichiasis can be cured by surgery prevents many from seeking treatment. Lack of understanding of what will be entailed (time, money, pain) is another a barrier.

- Trust in outcome: Patients often fear the outcome of surgery, with justification. While there has been no assessment of outcome of routine cataract surgery in Africa, some outcomes are less than desirable. A few bad outcomes can discourage a whole community.

- Cultural and social barriers: Cataract occurs more frequently in females, yet a population based study in KwaZulu Natal, South 
Africa, demonstrated that females underwent cataract surgery at only three fifths the rate of males. ${ }^{18}$ This may be due to less education, social support, and control of time and money among females compared with males.

A recent study in Malawi of the barriers that prevent the use of surgical services by children who could benefit suggest some differences from adult blind populations. Parents who were illiterate and whose children were residents at a blind school were least likely to accept surgery for their children. ${ }^{85}$ The study suggests that sustained educational efforts are needed with parents of blind children to ensure the best use of eye care services.

\section{The future}

VISION 2020 AND AFRICA

The Vision 2020 initiative refers to goals and priorities (described in the WHO/PBL/97.61 global initiative for the elimination of avoidable blindness) that are being adopted by many individuals, non-government development organisations, the WHO, government agencies, and ministries of health that work in the field of prevention of blindness. Its aim is to decrease the current projection of 75 million blind by the year 2020 to 25 million. The major causes of blindness in poor countries can be divided into three groups: (1) those which occur universally and for which there are successful cost effective treatments, including cataract and refractive errors; (2) those which occur among specific populations and which can be prevented by inexpensive medicines, including vitamin A deficiency, trachoma, and onchocerciasis; and (3) major blinding diseases that are less well defined and for which cost effective screening and treatment for poor people do not currently exist, including diabetic retinopathy and glaucoma ${ }^{86}$ For Africa, it is important to put high priority on the first two of these groups. In order to do so there will have to be tremendous developments in staffing, infrastructure, and organisational capacity.

The cataract surgical rate (CSR) is defined as the number of cataract operations performed per year per million population. At present the CSR in Africa is estimated to be 200-400; this can be compared with 4000 6000 in industrialised countries. The target for the next $5-10$ years is to increase the CSR in Africa to $2000 .^{87}$ This increase in the cataract surgical rate will necessitate more ophthalmologists (or cataract surgeons) working more efficiently and, equally important, much greater efforts to get the cataract blind to come forward for surgery. Specific programmes must be developed to meet these goals. The long term goal in Vision 2020 is to have one ophthalmologist per 250000 population and a cataract surgical rate of 4000 . This will keep up with the incident cataract blind and the backlog will be whittled away gradually.

An ophthalmologist/cataract surgeon needs a number of other health workers (ophthalmic medical assistants or nurses) to support him/her in order to work most efficiently. In addition, these health workers are vital in dealing with refractive error and the preventable causes of blindness in group 2. The Vision 2020 goal is to have one ophthalmic medical assistant or nurse per 200000 population within 10 years and to increase this to $1: 100000$ by the year 2020 .

Focal diseases such as trachoma, onchocerciasis, and vitamin A deficiency related blindness are generally being managed through primary health interventions. Eliminating blindness due to these diseases is the goal of a number of initiatives that come under the Vision 2020 structure.

Trachoma control (through the SAFE programme: $S$, surgery, $A$, antibiotics, $F$, facial cleanliness, and $E$, environmental change) is being promoted through the Alliance for the Global Elimination of Trachoma (GET 2020) which seeks to eliminate trachoma as a cause of blindness by the year 2020. The bilamellar tarsal rotation procedure is recommended by WHO for correcting trichiasis; this procedure and the similar Trabut procedure are used widely in Africa by a range of eye health providers. Outcomes vary, partly because of the skills of the surgeon, the presurgery condition of the lid (and pre-existing corneal damage), and the sometimes relentless progression of conjunctival scarring. Since trichiasis is the result of severe active disease in childhood, trichiasis surgery will remain an important ophthalmological procedure in Africa for many more decades. The International Trachoma Initiative is promoting large scale trachoma control efforts in five countries, including Ghana, Mali, and Tanzania in sub-Saharan Africa. It is hoped that expansion of these efforts to other areas and countries in the coming years will reduce trachoma significantly.

Onchocerciasis has been effectively managed in some countries of west Africa through a combination of spraying and drug distribution methods; this has been a costly undertaking but successful in that transmission has been eliminated. In other countries of Africa community based distribution of ivermectin has reduced the burden of onchocerciasis to manageable levels in many countries.

Vitamin A deficiency is being addressed by a number of strategies usually integrated into primary health care, nutrition, and immunisation programmes. Because local conditions responsible for this deficiency vary different strategies including vitamin A capsule distribution, fortification of certain foods with vitamin $\mathrm{A}$, and education to change dietary habits must be employed in different areas. As with all other aspects of health care, governments must be encouraged to recognise the problem and make a commitment to changing it.

\section{COMMUNITY OPHTHALMOLOGY}

The concept of community based medicine was outlined in the Alma Ata Declaration of 1978. Its tenets include the concept that a community has some responsibility for its own health and that healthcare schemes must be based on principles acceptable to and practical 
in the community. This has implications for prevention of blindness efforts. There may be a great gap in what the ophthalmologist in an urban clinic perceives as the problems in his area and what actually exists in the community. Examination of the problem in the community (through population based assessments) not only reveals the true magnitude of the problem and the specific subpopulations (which might not come to an urban ophthalmology clinic) affected, but it also provides information on what prevents people from using existing services. From such information, practical solutions can be developed. Much of this work will be done by non-ophthalmologists, such as paramedical personnel and professionals with skills in epidemiology, anthropology, social work, health economics, and management. However, the ophthalmologist will often be looked to for leadership and policy decisions and thus must be familiar with the multifaceted nature of blindness in the area. The effective African ophthalmologist must wear many hats in addition to that of surgeon/clinician including those of teacher/trainer, programme designer and manager, administrator, and research scientist. Standard clinical training does not equip one adequately for meeting these challenges. Community ophthalmology is ophthalmology from a public health perspective and it includes training in survey methodology, needs assessments, proper data collection and interpretation, communication and teaching skills, programme design and implementation, and effective administration. It is not a substitute for clinical training; instead, it complements clinical training to improve efficiency and effectiveness. A legion of ophthalmologists trained only in recognition and treatment of eye disease will not prevent blindness in Africa. If the goals of Vision 2020 are to be met, community ophthalmology must be practised.

1 Négrel A-D, Avognon Z, Minassian DC, et al. La cécité au Benin. Med Trop 1995;55:409-14.

2 Wilson MR, Mansour M, Ross-Degnan D, et al. Prevalence and causes of low vision and blindness in the extreme north province of Cameroon, West Africa. Ophthalmic Epidemiol 1996;3:23-33.

3 Schwartz EC, Huss R, Hopkins A, et al. Blindness and visual impairment in a region endemic for onchocerciasis in the Central African Republic. Br F Ophthalmol 1997;81:443-7.

4 Négrel A-D, Massemob-Yako B, Botaka E, et al. Prévalence et causes de la cécité au Congo. Bull Organ mond Santé 1990;68:237-43.

5 Cerulli L, Decrone C, Assefa C, et al. Assessment of visual status of the population in seven regions of Ethiopia. Rev Int Trach 1984;2:127-35.

6 Zerihun N, Mabey D. Blindness and low vision in Jimma Zone, Ethiopia: results of a population-based survery. Ophthalmic Epidemiol 1997;4:19-26.

7 Courtright P, Klungsøyr, Lewallen S. The epidemiology of blindness and visual loss in Hamar tribesmen of Ethiopia. The role of gender. Trop Geogr Med 1993;45:168-70.

8 Faal H, Minassian D, Sowa S, et al. National survey of blindness and low vision in the Gambia: results. $\mathrm{Br} \mathcal{F} \mathrm{Oph}$ thalmol 1989;73:82-7

9 Moll AC, van der Linden JH, Hogeweg M, et al. Prevalence of blindness and low vision of people over 30 years in the Wenchi district, Ghana, in relation to eye care programmes. Br f Ophthalmol 1994;78:275-9.

10 Whitfield R, Schwab L, Ross-Degnan D, et al. Blindness and eye disease in Kenya: ocular status survey results from the Kenya Rural Blindness Prevention Project. Brf Ophthalmol 1990;74:333-40.

11 Chirambo MC, Tielsch JM, West Jr KP, et al. Blindness and visual impairment in southern Malawi. Bull World Health visual impairment in sout

12 Kortlang C, Koster JCA, Coulibaly S, et al. Prevalence of blindness and visual impairment in the region of Ségou,
Mali. A baseline survey for a primary eye care programme. Trop Med Int Health 1996;1:314-19.

13 Kabo AM. Prévalence de la cécité au Niger. Rev Ocul Trop Subtrop Santé Publ 1983:55-62.

14 Akogun OB. Eye lesions, blindness and visual impairment in the Taraba river valley, Nigeria and their relation to onchocercal microfilariae in skin. Acta Trop 1992;51:1439.

15 Ezepue UF. Magnitude and causes of blindness and low vision in Anambra State of Nigeria (results of 1992 point relevance survey). Public Health 1997;111:305-9.

16 Adeoye A. Survey of blindness in rural communities of south-western Nigeria. Trop Med Int Health 1996;1:672-6.

17 Cook CD, Knight SE, Crofton-Briggs I. Prevalence and causes of low vision and blindness in northern KwaZulu. $S$ Afr Med $\mathcal{F} 1993 ; 83: 590-3$.

18 Bucher PJM, Ijsselmuiden CB. Prevalence and causes of blindness in the northern Transvaal. BrF Ophthalmol 1988; 72:721-6.

19 Tizazu T, Mburu FM. Prevalence and causes of vision loss in southern Sudan. Soc Sci Med 1983;17:1785-8.

20 Rapoza PA, West SK, Katala SJ, et al. Prevalence and causes of vision loss in central Tanzania. Int Ophthalmol 1991;15: 123-9.

21 Balo K, Negrel DA. Les causes de cécité au Togo. 7 Fr Ophtalmol 1989;12:291-5.

22 Sukwa TY, Mwandu DH, Ngalande TC, et al. Prevalence of blindness and visual impairment in the Luapula Valley, Zambia. Trop Geograph Med 1988;40:237-40.

23 Abou-Gareeb I, Lewallen S, Bassett K, et al. Gender and blindness: a meta-analysis of population-based prevalence surveys. Ophthalmic Epidemiol 2001;8:39-56.

24 Leske CM, Wu SY, Nemesure B, et al. Incidence and progression of lens opacities in the Barbados Eye Study. Ophthalmology 2000;107:1267-73.

25 West SK, Munoz B, Schein OD, et al. Racial differences in lens opacities: the Salisbury Eye Evaluation (SEE) project. Am f Epidemiol 1998;1:1033-9.

26 Munoz B, Aron J, Turner V, et al. Incidence estimates of late stages of trachoma among women in a hyperendemic area of central Tanzania. Trop Med Intl Health 1997;2:1030-8.

27 West SK, Munoz B, Turner VM, et al. The epidemiology of trachoma in central Tanzania. Int $\mathcal{F}$ Epidemiol 1991;20: 1088

28 West SK, Congdon N, Katala S, et al. Facial cleanliness and risk of trachoma in families. Arch Ophthalmol 1991;109: $855-7$.

29 Dolin PJ, Faal H, Johnson GJ, et al. Trachoma in the Gambia. Br f Ophthalmol 1998;82:930-3.

30 Emerson PM, Lindsay SW, Walraven GEL, et al. Effect of fly control on trachoma and diarrhoea. Lancet 1999;353: $1401-3$.

31 Schemann JF, Sacko D, Banou A, et al. Cartographie du trachome au Mali: resultats d'une enquete nationale. Bull World Health Organ 1998;76:599-606.

32 Hoechsmann A, Metcalfe N, Kanjaoloti S, et al. Reduction of trachoma in the absence of antibiotic treatment: evidence from a population-based survey in Malawi. Ophthalmic Epidemiol 2001;8(in press)

33 Wolfson EM, Fedewa L, Young SA. Trachoma: a women's health issue. Revised ed. The Global Alliance for Women's Health, 1999 .

34 Verrey JD, Foster A, Wormald R, et al. Chronic glaucoma in Northern Ghana-a retrospective study of 397 patients. Eye 1990;4:115-20.

35 Buhrmann RR, Quigley HA, Barron Y, et al. Prevalence of glaucoma in a rural east African population. Invest Ophthalmol Vis Sci, 2000;41:40-8.

36 Salmon JF, Mermoud A, Ivey A, et al. The prevalence of primary angle closure glaucoma and open angle glaucoma in mary angle closure glaucoma and open angle glaucoma in 1993;111:1263-9.

37 Tielsch JM, Sommer A, Katz J, et al. Racial variations in the prevalence of primary open angle glaucoma: the Baltimore Eye Study. $\mathscr{F A M A} 1991 ; 226: 369-74$

38 Wallace J, Lovell HG. Glaucoma and intraocular pressure in Jamaica. Am f Ophthalmol 1969;67:93-100

39 Mason RP, Kosoko O, Wilson MR, et al. National survey of the prevalence and risk factors of glaucoma in St Lucia, West Indies. Part I:prevalence findings. Ophthalmology 1989;96:1363-8.

40 Leske MC, Connell AMS, Schachat AP, et al the Barbados Eye Study Group. The Barbados Eye Study; prevalence of open angle glaucoma. Arch Ophthalmol 1994;12:821-9.

41 Burnham G. Onchocerciasis. Lancet 1998;351:1341-6.

42 Ilsar M. Chirambo M. Belkin M. Ocular injuries in Malawi. Br f Ophthalmol 1982;66:145-8.

43 Abraham D, Vitale S, West S, et al. Epidemiology of eye injuries in rural Tanzania. Ophthalmic Epidemiol 1999;6:8594.

44 Mselle J. Visual impact of using traditional medicine on the injured eye in Africa. Acta Trop 1998;70:185-92.

45 Lewallen S, Courtright P. Peripheral corneal ulcers associated with use of African traditional eye medicines. $\mathrm{Br}$ f Ophthalmol 1995;79:343-6.

46 Courtright P, Lewallen S, Kanjaloti S, et al. Traditional eye medicine use among patients with corneal disease in rural Malawi. Br f Ophthalmol. 1994;78:810-2.

47 Sobngwi E, Mbanya JC, Moukouri EN, et al. Microalbuminuria and retinopathy in a diabetic population of Cameroon. Diabetes Res Clin Pract 1999;44:191-6.

48 Sidibe EH. Diabetic retinopathy in Dakar and African literature review:epidemiologic elements. Diabetes Metab 2000;26:322-4 
49 Levitt NS, Bradshaw D, Zwarenstein MF, et al. Audit of public sector primary diabetes care in Cape Town, South Cancontrolled hyperglycaemia, and hypertension. Diabet Med 1997;14 1073-7.

50 Kalk WJ, Joannou J, Ntsep S, et al. Ethnic differences in the clinical laboratory associations with retinopathy in adult onset diabetes: studies in patients of African, European and Indian origin. $\mathcal{F}$ Intern Med 1997;24:31-7.

51 Drabo PY, Kabore J. Lengani A. Complications of diabetes mellitus at the Hospital Center of Ouagadougou. Bull Soc Pathol Exot 1996;89:191-5.

52 Elbagir MN, Eltom MA, Mahadi EO, et al. Pattern of longterm complications in Sudanese insulin-treated diabetic patients. Diabetes Res Clin Pract 1995;30:59-67.

53 Kaimbo DK, Kabongo BK, Missotten L. Ocular complications in diabetes mellitus in Zaire. Bull Soc Belge Ophthalmol 1995;255:107-13.

54 Lester FT. Clinical features, complications and mortality in type 2 (non-insulin dependent) diabetic patients in Addis type 2 (non-insulin dependent) diabetic patients in Addis 26.

55 Gordon YJ, Mokete M. Diabetic retinopathy in Lesotho. Doc Ophthalmol 1981;15:193-8.

56 Erasmus RT, Alanamu RA, Bojuwoye B, et al. Diabetic retinopathy in Nigerians: relation to duration of diabetes, type of treatment and degree of control. East Afr Med $\mathcal{F}$ 1989;66:248-54.

57 Gilbert CE, Anderton L, Dandona L, et al. Prevalence of visual impairment in children: a review of available data. Ophthalmic Epidemiol 1999;6:73-82.

58 Foster A, Gilbert C. Epidemiology of childhood blindness. Eye 1992;6:172-6.

59 Gilbert C, Canovas R, Hagan M, et al. Causes of childhood blindness: results from West Africa, South India, and Chile. Eye 1993;7:184-8.

60 Schwab L, Kagame K. Blindness in Africa: Zimbabwe schools for the blind survey. British fournal of Ophthalmol schools for the blind

61 Ggy, 1993;77:410-12. Waddel K, et al. Causes of childhood blindness in East Africa: results in 491 pupils attending 17 blindness in East Africa: results in 491 pupils attending 17
schools for the blind in Malawi, Kenya and Uganda. Ophschools for the blind in Malawi,

62 McLaren DS, Frigg M. Sight and life manual on vitamin $A$ deficiency disorders (VADD). 2nd ed. Basle: Task Force Sight and Life, 2001

63 Sommer A, West KP. Vitamin A deficiency: health, survival, and vision. New York: Oxford University Press, 1996:191220.

64 Leprosy - global situation. Weekly Epidemiol Record 2000;28: 226-31.

65 Waddell KM, Saunderson PR. Is leprosy blindness avoidable? The effect of disease type, duration, and treatment on eye damage form leprosy in Uganda. $\mathrm{Br} \mathcal{F}$ Ophthalmol 1995;79:250-356.

66 Courtright P, Lewallen S. Current concepts in the surgical management of lagophthalmos in leprosy. Leprosy Rer management

67 Lewallen S, Lowdon R, Courtright $\mathrm{P}$, et al. A populationbased study of the prevalence of refractive error in Malawi. Ophthalmic Epidemiol 1995;2:145-9.
68 Lo PI, Ho PC, Lau JT, et al. Relationship between myopia and optical components - a study among Chinese Hong Kong student population. Yen Ko Hsueh Pao 1996;12:1215.

69 Zhao J, Pan X, Sui R, et al. Refractive error study in children: results from Shunyi District, China. Am $\mathcal{F}$ Ophthalmol 2000;129:427-35.

70 Wong TY, Foster PJ, Hee J, et al. Prevalence and risk factors for refractive error in adult Chinese in Singapore. Invest Ophthalmol Vis Sci 2000;41:2486-94.

71 Herse P. An ophthalmic survey of African patients presenting at rural eye clinics in South Africa. Optometry Vis $S c i$ 1991;68:738-42.

72 Umeh RE. The causes and profile of visual loss in an onchocerciasis-endemic forest-savanna zone in Nigeria. Ophthalmic Epidemiol 1999;6:303-15.

73 Kamali A, Whitworth JAG, Ruberantwari A, et al. Causes and prevalence of non-vision impairing ocular conditions among a rural adult population in SW Uganda. Ophthalmic Epidemiol 1999;6:41-8.

74 Nwosa SN. Prevalence and pattern o retinal diseases at the Guiness Eye Hospital, Onitsha, Nigeria. Ophthalmic Epidemiol 2000;7:41-8.

75 Fafowara OF, Osuntokun OO. Age related eye disease in the elderly members of rural African community. East Afr Med f 1997;74:435-7.

76 Lewallen S. Herpes zoster ophthamicus in Malawi. Ophthalmology 1994;101:1801-4

77 Waddell KM, Lewallen S, Lucas SB, et al. Carcinoma of the conjunctiva and HIV infection in Uganda and Malawi. $\mathrm{Br}$ f Ophthalmol 1996;80:503-8.

78 Kestelyn P. The epidemiology of CMV retinitis in Africa. Ocular Immunol Inflamm 1991;7:173-7.

79 Foster, A. Who will operate on Africa's 3 million curably blind people? Public Health 1991;337:1267-9.

80 West S, Lynch M, Munoz B, et al. Predicting surgical compliance in a cohort of women with trichiasis. Int Ophthalmol 1994;18:105-9.

81 Courtright P. Acceptance of surgery for trichiasis among rural Malawian women. East Afr Med f 1994;71:35-6.

82 Courtright $\mathrm{P}$, Kanjoloti S, Lewallen S. Barriers to acceptance of cataract surgery among patients presenting to district hospital in rural Malawi. Trop Geograph Med 1995;47:15-18.

83 Johnson JG, Goode Sen V, Faal H. Barriers to the uptake of cataract surgery. Trop Doct 1998;28:218-20.

84 Bowman RJ, Soma OS, Alexander N, et al. Should trichiasis surgery be offered in the village? A community randomised trial of village vs health centre-based surgery. Trop Med Int Health 2000;5:528-33.

85 Van Dijk K, Courtright P. Barriers to surgical intervention among blind and low vision children in Malawi. Visual Impairment Res 2001;2:75-9.

86 Foster A. Vision 2020: the right to sight. IAPB News, no 25, January 2000. International Agency for the Prevention of Blindness. Secretariat: LV Prasad Eye Institute, LV Prasad Marg, Banjara Hills, Hyderabad 500 034, India.

87 Foster A. Cataract-a global perspective: output, outcome and outlay. Eye 1999;13:449-53. 